\title{
Are Hypotension and Rash After Atracurium Really Caused by Histamine Release?
}

\author{
Alfred Doenicke, MD*, Jonathan Moss, MD, PhDt, Wilfried Lorenz, MD \\ Rainer Hoernecke, $\mathrm{MD}^{*}$, and Marco Gottardis, $\mathrm{MD}^{*}$ \\ *Institute of Anesthesiology, Ludwig Maximilians University of Munich, Munich, Germany; +Department of Anesthesia \\ and Critical Care, University of Chicago, Chicago, Illinois; and łInstitute of Theoretical Surgery, \\ Philipps University of Marburg, Marburg, Germany
}

\begin{abstract}
A prospective, randomized, double-blind study was performed in 40 patients (ASA class I-III) treated with atracurium to ascertain whether histamine release caused hemodynamic or cutaneous changes. The treated group of 20 patients was premedicated with the $\mathrm{H}_{1}$ antagonist dimetindene $(0.2 \mathrm{mg} / \mathrm{kg})$ and the $\mathrm{H}_{2}$ antagonist ranitidine $(1.25 \mathrm{mg} / \mathrm{kg})$; the control group of 20 patients received saline. Six minutes after the induction of anesthesia with thiopental/fentanyl, patients received atracurium $0.5 \mathrm{mg} / \mathrm{kg}$ over $5 \mathrm{~s}$. Plasma histamine levels were measured fluorometrically $5 \mathrm{~min}$ after administration of thiopental/fentanyl and 2 and 5 min after atracurium. Arterial blood pressure and heart rate were recorded every $2 \mathrm{~min}$. Histamine levels $(0.24 \mathrm{ng} / \mathrm{mL})$ did not change significantly after thiopental/fentanyl. In the control group, 2 min after injection of atracurium, plasma histamine levels were $0.76 \pm 0.76 \mathrm{ng} / \mathrm{mL}$, and in the antihistamine-treated
\end{abstract}

group, $0.39 \pm 0.24 \mathrm{ng} / \mathrm{mL}(P<0.05$ control versus treated), suggesting that pretreatment with antihistamines may attenuate atracurium-induced histamine release. Systolic and diastolic blood pressure decreased significantly in both groups after thiopental $(P<0.05)$, but did not decrease further after the administration of atracurium. There were cutaneous manifestations in 7 of 20 patients in the control group and in none of the 20 patients treated with $\mathrm{H}_{1}$ and $\mathrm{H}_{2}$ antagonists $(P<$ 0.0005). We conclude that atracurium caused modest histamine release in our patients but that the decrease in arterial blood pressure may have been due, in part, to thiopental. Cutaneous manifestations of histamine release did not correlate with hemodynamic events or with plasma histamine levels, but were prevented with antihistamine pretreatment.

(Anesth Analg 1994;78:967-72)
$\mathrm{M}$ any muscle relaxants, anesthetic drugs, and adjuvants may cause the increase of plasma histamine levels by nonimmunologic mechanisms. Whether patients should be pretreated with $\mathrm{H}_{1}$ and $\mathrm{H}_{2}$ antagonists to prevent histamine release during anesthesia and surgery has been debated for $20 \mathrm{yr}$ (1). Recently, much of the debate has focused on atracurium. Although its formulation does not contain solvents that interfere with its action or elicit histamine release, depending upon dose of atracurium and speed of administration, histamine may be released (2-4). Administration of atracurium has been associated with hypotension and increased plasma histamine levels (3-5), but the temporal proximity of the administration of the drug used for inducing anesthesia and atracurium makes interpretation of these hemodynamic changes difficult. In addition,

Accepted for publication December 21, 1993.

Address correspondence to Jonathan Moss, MD, PhD, Department of Anesthesia and Critical Care, University of Chicago, 5841 S. Maryland Ave., MC-4028, Chicago, IL 60637. thiopental, fentanyl, and atracurium all can induce cutaneous reactions, making it unclear whether the cutaneous manifestations of histamine release can be attributed to atracurium in the clinical setting. We performed a double-blind, randomized, placebo-controlled trial in two groups of 20 patients each to ascertain whether low levels of histamine release associated with atracurium administration would cause significant hemodynamic or cutaneous changes, and whether these changes could be attenuated by prophylactic administration of an antihistamine. Our study differs from previous studies (4) in which increased histamine levels were the source of greatest interest, but antihistamines were not used.

\section{Methods}

After the study was reviewed and authorized by our institutional review board, 40 patients were enrolled in the study according to the following inclusion criteria: age $>18 \mathrm{yr}$, body weight between 50 and $100 \mathrm{~kg}$, and preoperative ASA grade I-III. Patients were scheduled 


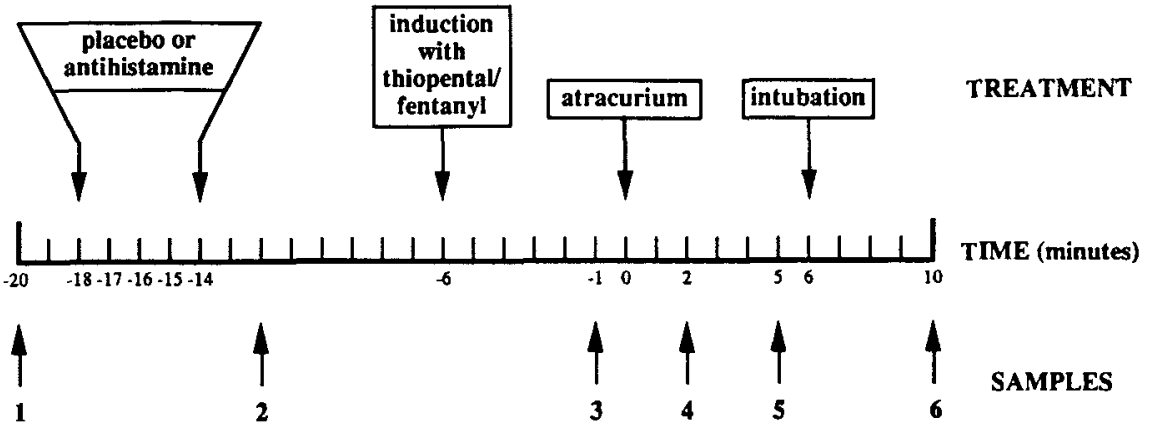

Figure 1. Schedule for drug administration and sampling.

for elective surgery under general anesthesia. Excluded were pregnant or breast-feeding women, patients who had taken $\mathrm{H}_{1}$ - or $\mathrm{H}_{2}$ - receptor antagonists or corticosteroids up to $1 \mathrm{wk}$ before surgery, and patients with a history of atopy, asthma, or previous reactions after intravenous medication. All patients gave their written informed consent. Except for one total gastrectomy, all operations were minor surgical procedures, in order to minimize parenteral histamine release from surgical manipulations.

Patients were randomly allocated by a random number table to the treated $\left(\mathrm{H}_{1}+\mathrm{H}_{2}\right)$ or to the control group on the morning of the operation. The evening before, and on the morning of surgery, all patients were premedicated with oral lormetazepam (1-2 mg per os), a drug not associated with histamine release. An anesthetic nurse injected coded solutions $\left(\mathrm{H}_{1}+\mathrm{H}_{2}\right.$ or control) into an infusion bottle containing $50 \mathrm{~mL}$ of saline $0.9 \%$ to guarantee the double-blind condition and the stability of the drug mixture. The $\mathrm{H}_{1}$ antagonist dimetindene $(0.2 \mathrm{mg} / \mathrm{kg})$ and the $\mathrm{H}_{2}$ antagonist ranitidine $(1.25 \mathrm{mg} / \mathrm{kg})$ or equal volumes of control solution were administered as a slow infusion 14 to $18 \mathrm{~min}$ before injection of atracurium to permit adequate antagonism and minimize the possibility of increase in plasma levels of histamine due to dimetindene and ranitidine. Anesthesia was induced with fentanyl $(3 \mu \mathrm{g} / \mathrm{kg}$ intravenously) and thiopental ( $4 \mathrm{mg} / \mathrm{kg}$ intravenously over 30 s) and maintained with enflurane $(0.4 \%-1 \%$ inspired concentration), $\mathrm{N}_{2} \mathrm{O} / \mathrm{O}_{2}$. Atracurium $(0.5 \mathrm{mg} / \mathrm{kg})$ was given $6 \mathrm{~min}$ after thiopental as a bolus injection over 5 $\mathrm{s}$. The trachea was intubated $6 \mathrm{~min}$ after injection of atracurium. Hemodynamic and clinical variables were measured every 2 min for technical reasons and blood samples for histamine determination were taken before (baseline) and after premedication, $5 \mathrm{~min}$ after thiopental ( $1 \mathrm{~min}$ before atracurium), 2 and $5 \mathrm{~min}$ after atracurium, and $4 \mathrm{~min}$ after intubation (Figure 1, Sample 6).

Plasma histamine concentrations were measured using the fluorometric-enzymatic method. This assay has a sensitivity of $20 \mathrm{pg} / \mathrm{mL}(6,7)$. None of the drugs or drug formulations interfered with the fluorometric assay at concentrations up to $10^{-3} \mathrm{~mol} / \mathrm{L}$.
Heart rate was measured by electrocardiogram (lead II) via a Siemens monitor. Arterial blood pressure (systolic, diastolic) was measured using an oscillometer and was documented every $2 \mathrm{~min}$ (three times each after thiopental and after atracurium). Cutaneous manifestations of histamine release were assessed by an investigator blinded to the study. Skin changes were graded as flush, constant redness (if longer than $120 \mathrm{~s}$ ), erythema, or wheals.

Rank paired $t$-test was used to compare continuous variables within a group, and unpaired $t$-test was used for intergroup comparisons. Data are presented as mean $\pm \mathrm{SD}$. Noncontinuous variables were analyzed by Fisher's exact test. We used the criteria of Lorenz and Neugebauer (6) to establish causality. This analysis considers the problem of attribution of causality (i.e., histamine release, cutaneous or hemodynamic changes) during a sequence of events (drug administration, intubation).

\section{Results}

There were no significant differences between the treated and control groups in age (36 [22-71] yr treated vs 35 [18-54] yr control), gender ( 16 males treated vs 13 males control), weight, type of procedure (predominantly general surgery $>$ orthopedic $>$ urology), or ASA classification, except two patients in the antihistamine group were ASA grade III.

Systolic blood pressure decreased significantly after thiopental/fentanyl nitrous oxide and enflurane in both groups (Figure 2). In the control group, mean systolic blood pressure decreased from $135 \mathrm{~mm} \mathrm{Hg}$ to 103 $\mathrm{mm} \mathrm{Hg}$, and in the treated group from 147 to $105 \mathrm{~mm}$ $\mathrm{Hg}$, but there were no significant differences between groups. Upon administration of the first dose of atracurium, there was no statistically detectable further decrease in systolic blood pressure. Diastolic changes mirrored systolic changes. In the control group, no patient exhibited a decrease in systolic blood pressure of $>20 \%$ after the administration of atracurium. In the antihistamine-pretreated group, systolic blood pressure decreased $>20 \%$ in two patients, one of whom experienced coincident histamine release (Table 1). In this 


\section{Systolic Blood Pressure, $n=40$}

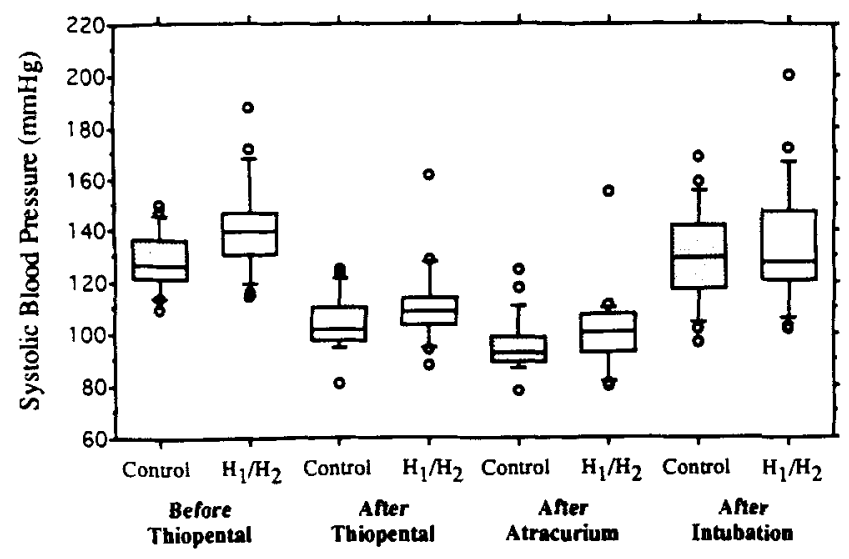

Figure 2. Box plot of systolic blood pressure for control and antihistamine-treated groups. This format presents the first and third quartiles as top and bottom of box, median as middle line, and 90th percentile as whiskers. Outlying points $(<2 \mathrm{sD})$ are given by open circles. Although there was a significant decrease in systolic blood pressure in both placebo and antihistamine-treated groups after thiopental $(P<0.05)$, no further change was seen after atracurium in either group.

patient (no. 16), systolic blood pressure decreased after thiopental administration from 150 to $100 \mathrm{~mm} \mathrm{Hg}$, and subsequently after atracurium administration to 93 $\mathrm{mm} \mathrm{Hg}$. These hemodynamic changes were associated with an increase in plasma histamine levels from 0.21 $\mathrm{ng} / \mathrm{mL}$ to $2.31 \mathrm{ng} / \mathrm{mL} 2 \mathrm{~min}$ after atracurium, and 1.55 $\mathrm{ng} / \mathrm{mL} 3 \mathrm{~min}$ later. No change in heart rate was detected in this patient.
In the control group, heart rate increased $>20 \%$ in five patients and decreased $>20 \%$ in two patients after thiopental and fentanyl administration. Heart rate remained unchanged in 11 patients. After atracurium, heart rate did not change in either group (Table 1, Figure 3). In the antihistamine-treated group mean heart rate decreased from $85.5 \pm 2.5$ beats $/ \mathrm{min}$ to $70.4 \pm 2.4$ beats/min after thiopental $(P<0.001)$ and further decreased to $64.6 \pm 1.7$ beats $/ \mathrm{min}$ after atracurium $(P<0.001)$. After intubation the heart rate increased to $84.6 \pm 3.1$ beats $/ \mathrm{min}(P<0.005$ vs previous value $)$ Values for the control group were virtually identical. Differences in heart rate were not statistically different between groups for similar intervals.

The mean plasma histamine concentration in the control and antihistamine-treated groups was virtually identical $(0.24 \pm 0.13$ and $0.24 \pm 0.10 \mathrm{ng} / \mathrm{mL})$ and remained statistically unchanged after thiopental administration (Figure 4). The mean concentration $2 \mathrm{~min}$ after the administration of atracurium was $0.76 \pm 0.76$ $\mathrm{ng} / \mathrm{mL}$ in the control group and $0.39 \pm 0.24 \mathrm{ng} / \mathrm{mL}$ in the antihistamine-treated group $(P<0.04 \mathrm{vs}$ control group; $P<0.02$ versus prior sample).

Although plasma histamine levels remained in the physiologic range in both groups, there was a marked attenuation of atracurium-induced histamine release in the antihistamine-pretreated group $(0.76 \pm 0.76$ vs 0.39 $\pm 0.24 ; P<0.05$; Figure 4). When considered on an individual basis, histamine release occurred after atracurium in 16 patients, 11 in the control group and 5 in the antihistamine-pretreated group (Table 2).

Table 1. Arterial Blood Pressure and Heart Rate During Induction of Anesthesia in Relation to Plasma Histamine Levels

\begin{tabular}{|c|c|c|c|c|}
\hline & \multicolumn{2}{|c|}{$\begin{array}{l}\text { After thiopental } 4 \mathrm{mg} / \mathrm{kg} \\
\text { and fentanyl } 3 \mu \mathrm{g} / \mathrm{kg}\end{array}$} & \multicolumn{2}{|c|}{ After atracurium $0.5 \mathrm{mg} / \mathrm{kg}$} \\
\hline & $\begin{array}{l}\text { Histamine } \\
\text { release }\end{array}$ & $\begin{array}{l}\text { No histamine } \\
\text { release }\end{array}$ & $\begin{array}{l}\text { Histamine } \\
\text { release }\end{array}$ & $\begin{array}{l}\text { No histamine } \\
\text { release }\end{array}$ \\
\hline Placebo group $(n=20)$ & $n=2$ & $n=18$ & $n=12$ & $n=8$ \\
\hline \multicolumn{5}{|l|}{ Heart rate } \\
\hline Decrease $>20 \%$ & 0 & 2 & 0 & 0 \\
\hline Increase $>20 \%$ & 1 & 5 & 0 & 0 \\
\hline Unchanged & 1 & 11 & 12 & 8 \\
\hline \multicolumn{5}{|l|}{ Blood pressure } \\
\hline Systolic decrease $>20 \%$ & 2 & 13 & 0 & 0 \\
\hline Unchanged & & 5 & 12 & 8 \\
\hline Antihistamine group $(n=20)^{a}$ & & $n=20$ & $n=5$ & $n=15$ \\
\hline \multicolumn{5}{|l|}{ Heart rate } \\
\hline Decrease $>20 \%$ & & 6 & 0 & 0 \\
\hline Increase $>20 \%$ & & 3 & 0 & 0 \\
\hline Unchanged & & 11 & 5 & 15 \\
\hline \multicolumn{5}{|l|}{ Blood pressure } \\
\hline Systolic decrease $>20 \%$ & & 17 & 1 & 1 \\
\hline Systolic increase $>20 \%$ & & 0 & 0 & 1 \\
\hline Unchanged & & 3 & 4 & 13 \\
\hline
\end{tabular}

Patients were separated according to whether they exhibited hemodynamic response and histamine release.

${ }^{a}$ Dimetindene $0.2 \mathrm{mg} / \mathrm{kg}$; ranitidine $1.25 \mathrm{mg} / \mathrm{kg}$. 
This difference in incidence between control and antihistamine-treated groups did not achieve statistical significance $(2 P<0.11)$ (Fisher's exact test).

Two patients experienced significant increases of plasma histamine associated with the administration of atracurium. Aside from the patient described above, in one patient (No. 31) systolic blood pressure decreased from 145 to $126 \mathrm{~mm} \mathrm{Hg}$ associated with the induction of anesthesia. No further hemodynamic changes were noted after atracurium administration in the patient, although the plasma histamine level increased from $0.22 \mathrm{ng} / \mathrm{mL}$ after thiopental to $3.34 \mathrm{ng} / \mathrm{mL} 2 \mathrm{~min}$ after atracurium, with a level of $1.74 \mathrm{ng} / \mathrm{mL} 3 \mathrm{~min}$ later. In this patient, heart rate increased 12 beats $/ \mathrm{min}$ after thiopental administration, and an additional 12 beats / min after the administration of atracurium. In general, changes in heart rate appeared to be unrelated to histamine levels (Table 1). Heart rate did not decrease in the control group after the administration of atracurium, even with modestly increased plasma histamine levels.

We examined data regarding cutaneous manifestations by segregating patients who developed cutaneous signs from both the control and antihistaminetreated groups. In the control group, seven patients developed cutaneous signs after atracurium administration. Six patients demonstrated no cutaneous signs of histamine release despite an increase in plasma levels (Table 2). The remaining seven patients in the control group did not demonstrate an increase in plasma histamine concentrations or cutaneous signs (not included in Table 2). Plasma histamine levels of

\section{Heart Rate, $n=40$}

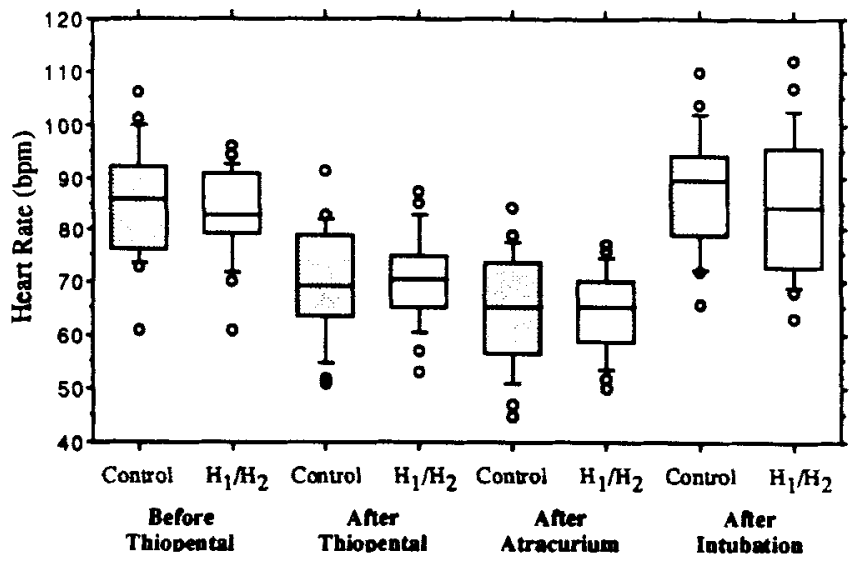

Figure 3. Box plot of heart rate for control of placebo and antihistamine groups. This format presents the first and third quartiles as top and bottom of box, median as middle line, and 90th percentile as whiskers. Outlying points $(>2 \mathrm{sD})$ are given by open circles. Although there was a significant decrease in heart rate after thiopental $(P<0.001)$ and a significant increase in heart rate after tracheal intubation $(P<0.001)$, these differences were the same in both the control and antihistamine-treated groups

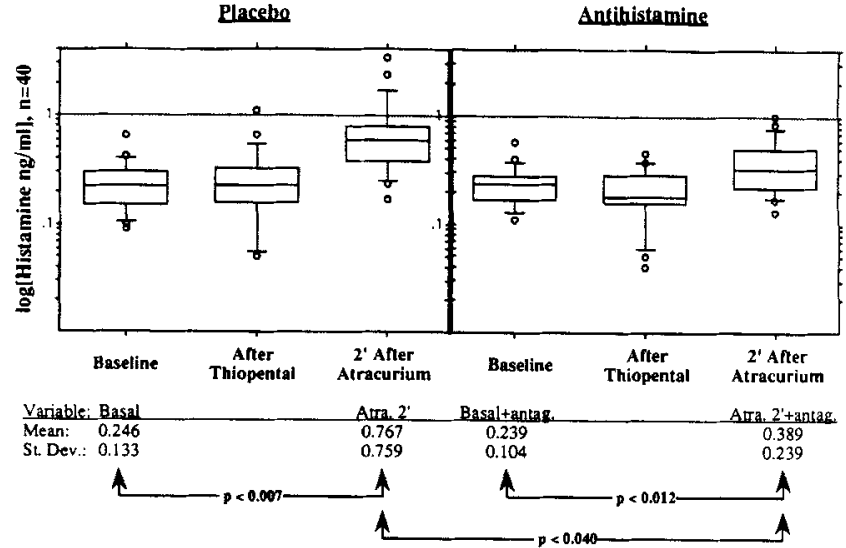

Figure 4. Box plot of plasma histamine of log histamine concentration at baseline and after drug administration. This format presents the first and third quartiles as top and bottom of box, median as middle line, and 90th percentile as whiskers. Outlying points ( $>2 \mathrm{sD}$ ) are given by open circles. Differences between intervals and groups are as indicated in the figure.

cutaneous reactors and nonreactors were not significantly different. In the antihistamine-pretreated group, none of the 20 patients experienced cutaneous signs of histamine release, but five patients showed an increase in plasma histamine levels from a mean of $0.23 \pm 0.09$ to $0.71 \pm 0.23 \mathrm{ng} / \mathrm{mL}(P<0.0005$ vs control). The difference between placebo and antihistamine pretreatment in incidence of cutaneous signs was statistically significant $(2 P=0.008$, Fisher's exact test). The corresponding differences in incidence of elevated plasma histamine $(11 / 20$ vs $5 / 20)$ were in the same direction but did not achieve statistical significance $(2 P=0.11$, Fisher's exact test).

\section{Discussion}

Atracurium is a known histamine releaser, both in vivo and in vitro $(4,5,8,9)$, but the proximity of its administration to the induction of anesthesia, as well as the speed of injection and dose, must be factors in considering the hemodynamic effects. Under our anesthetic regimen, in which thiopental and atracurium administration were widely separated, bolus administration of atracurium elicited only modest elevations in plasma histamine and these were without significant hemodynamic changes, even in the control group.

Hosking et al. (8) demonstrated the efficacy of combined $\mathrm{H}_{1}$ - and $\mathrm{H}_{2}$-receptor block in attenuating atracurium-induced hemodynamic affects. However, in their study the atracurium dose was $1.5 \mathrm{mg} / \mathrm{kg}$, approximately three times the normal dose for endotracheal intubation, and the associated plasma histamine levels were very high. In a study by Gallo et al. (5), atracurium was given so soon after thiopental that it 
Table 2. Plasma Histamine Levels of Patients With and Without Cutaneous Signs Who Exhibited Histamine Release After Atracurium

\begin{tabular}{|c|c|c|c|}
\hline Patient No. & $\begin{array}{l}\text { Plasma histamine } \\
\text { (ng/mL) prior } \\
\text { to atracurium }\end{array}$ & $\begin{array}{l}\text { Plasma histamine } \\
(\mathrm{ng} / \mathrm{mL}) 2 \mathrm{~min} \\
\text { after atracurium }\end{array}$ & $\begin{array}{c}\text { Cutaneous } \\
\text { signs }\end{array}$ \\
\hline \multicolumn{4}{|c|}{ Control group $(n=6)$ : plasma histamine concentration in patients without cutaneous signs } \\
\hline 2 & 0.34 & $0.68^{a}$ & 0 \\
\hline 7 & 0.36 & $0.58^{a}$ & 0 \\
\hline 10 & 0.29 & $0.75^{a}$ & 0 \\
\hline 11 & 0.14 & $1.04^{a}$ & 0 \\
\hline 16 & 0.21 & $2.31^{a}$ & 0 \\
\hline 21 & 0.17 & $0.47^{a}$ & 0 \\
\hline Mean & $0.25 \pm 0.09$ & $1.09 \pm 0.68$ & \\
\hline \multicolumn{4}{|c|}{ Control group ( $n=7$ ): plasma histamine concentration in patients with cutaneous signs } \\
\hline 6 & 0.65 & $0.86^{a}$ & CR \\
\hline 14 & 0.06 & $0.66^{a}$ & FL \\
\hline 23 & 0.05 & 0.17 & CR,ER \\
\hline 24 & 0.23 & $0.60^{a}$ & ER \\
\hline 31 & 0.22 & $3.34^{a}$ & ER \\
\hline 33 & 0.05 & 0.29 & FL,ER \\
\hline 39 & 0.11 & $0.81^{a}$ & ER \\
\hline Mean & $0.20 \pm 0.20$ & $0.96 \pm 1.08$ & \\
\hline \multicolumn{4}{|c|}{ Antihistamine group ( $n=5$ ): plasma histamine concentration in patients without cutaneous signs } \\
\hline 13 & 0.38 & $0.86^{a}$ & 0 \\
\hline 20 & 0.22 & $0.68^{a}$ & 0 \\
\hline 26 & 0.17 & $0.55^{a}$ & 0 \\
\hline 32 & 0.16 & $0.44^{a}$ & 0 \\
\hline 40 & 0.24 & $1.02^{a}$ & 0 \\
\hline Mean & $0.23 \pm 0.09$ & $0.71 \pm 0.23$ & \\
\hline
\end{tabular}

$\mathrm{CR}=$ constant redness; $\mathrm{ER}=$ erythema (spots); $\mathrm{FL}=$ flush

${ }^{a}$ Responder according to Lorenz and Neugebauer (6).

was difficult to discriminate between hemodynamic effects of the induction drug and atracurium. Other studies involving atracurium's effects on isolated organs and tissues reflect the functional heterogeneity of mast cells between species $(10,11)$. We therefore designed our study to explore the effects of atracurium-induced histamine release using the customary dose $0.5 \mathrm{mg} / \mathrm{kg}$ but under conditions that allowed us to discriminate between the effects of thiopental and the relaxant.

Based on our clinical experience and previous studies (5), we questioned whether the administration of atracurium at intubating doses was associated with hypotension and or cutaneous manifestations. Surprisingly, in our study, atracurium did not cause a further reduction in arterial blood pressure. Whether atracurium, when given in rapid sequence after the administration of thiopental and fentanyl, elicits a more profound hemodynamic change was not examined, although the study by Gallo et al. (5) suggests that this is the case. Because the hypotension we observed was related temporarily to thiopental and preceded atracurium administration, it presumably reflected barbiturate-mediated cardiac depression and was perhaps more apparent due to an experimental design in which intubation and its attendant stress were delayed.

Another clinical problem associated with the administration of atracurium is the appearance of local or systemic cutaneous manifestations, including redness, urticaria, wheals, and flush. In our study there was no relationship between plasma histamine levels achieved after atracurium and cutaneous manifestations. Six patients with modest elevations in plasma histamine levels experienced no cutaneous signs, whereas seven other patients with virtually identical levels experienced cutaneous signs (Table 2). The remaining seven patients had no increase in plasma levels and no cutaneous signs. The functional heterogeneity of mast cells could account for such differences. Previous studies using human mast cells from skin and lung tissue have demonstrated fundamental differences in the susceptibility of these cells to release histamine in response to atracurium. It may well be that plasma histamine levels are a poor reflection of the effect of drugs on skin mast cells $(11,12)$. None of our antihistamine-pretreated patients had any cutaneous manifestations associated with atracurium administration, although five had modest increases in plasma histamine levels (Table 2). 
Our data, therefore, suggest that the cutaneous manifestations associated with atracurium administration in usual doses are unlikely to be related to systemic hemodynamic changes or plasma histamine levels. However, these skin changes probably reflect local release of histamine because they are prevented by pretreatment with antihistamines.

Histamine can be released at low levels in a significant number of patients, perhaps without the full appreciation of the attending anesthesiologist. In the control group, six patients had elevations of plasma histamine levels, including one patient who achieved a level of $2.31 \mathrm{ng} / \mathrm{mL}$ without significant hemodynamic or cutaneous manifestations. It is therefore difficult for an anesthesiologist to judge whether the hypotension that occurs during the course of a normal anesthetic is secondary to histamine release, ganglionic block, or a variety of other side effects associated with anesthetic drugs and adjuvants. It is clear, however, from our results and other studies, that chemoprophylaxis with $\mathrm{H}_{1}$ and $\mathrm{H}_{2}$ antagonists can attenuate some of the clinical manifestations of histamine release, particularly rash and flush (13-16).

Although the receptor antagonist properties of antihistamines are the main contributory factors in attenuating the cardiovascular effects of histamine release (13-16), our study also demonstrates their effect on histamine levels. In our patients, the measured level of plasma histamine was significantly lower in the antihistamine-pretreated group. A series of studies in isolated mast cells and tissues has shown that superfused histamine will attenuate chemically induced release $(11,12,17,18)$. Our findings that histamine release is inhibited by antihistamines differ from those of Hoskings et al. (8), but both the absolute and evoked levels of histamine we observed were considerably less.

Although the presence of a rash after atracurium administration has been taken as a harbinger of significant cardiovascular changes, our experimental data suggest that this is not the case. Cutaneous manifestations of atracurium administration were independent of systemic levels of plasma histamine and of cardiovascular effects in our relatively healthy group of patients.

\section{References}

1. Lorenz W, Ennis M, Doenicke A, Dick W. Perioperative uses of histamine antagonists. I Clin Anesth 1990;2:345-60.

2. Hughes R, Chapple DJ. The pharmacology of atracurium: a new competitive neuromuscular blocking agent. Br J Anaesth 1981; 53:31-44.

3. Scott RPF, Savarese J], Basta SI, et al. Atracurium: clinical strategies for preventing histamine release and attenuating the hemodynamic response. Br J Anaesth 1985;57:550-3.

4. Barnes PK, De Renzy-Martin N, Thomas VJE, Watkins J. Plasma histamine levels following atracurium. Anaesthesia 1986;41: $821-4$.

5. Gallo JA, Cork RC, Puchi P. Comparison of effects of atracurium and vecuronium in cardiac surgical patients. Anesth Analg 1988; 67:161-5.

6. Lorenz $W$, Neugebauer E. Histamine determination: current techniques-fluorometric assays. In: Uvnas B, ed. Handbook of experimental pharmacology, vol 97. New York: Springer, 1990: 385-439.

7. Lorenz W, Doenicke A, Dietz W. Release of histamine $\mathrm{H}_{2}$-receptor antagonists. Lancet 1987;ii:1098.

8. Hosking MP, Lennon RL, Gronert GA. Combined $\mathrm{H}_{1-}+\mathrm{H}_{2-}$ receptor blockade attenuates the cardiovascular effects of highdose atracurium for rapid sequence endotracheal intubation. Anesth Analg 1988;67:1089-92.

9. Watkins J. Investigation of allergic and hypersensitivity reactions to anaesthetic agents. Br J Anaesth 1987;59:104-11.

10. Stellato $C$, Cirillo $R$, de Paulis A, et al. Human basophil/mast cell releasability. IX. Heterogeneity of the effects of opioids on mediator release. Anesthesiology 1992;77:932-40.

11. Little MM, Wood DR, Casale TB. Azelastine inhibits stimulated histamine release from human lung tissue in vitro but does not alter cyclic nucleotide content. Agents Actions 1992;28:16-21.

12. Platshon LF, Kaliner $M$. The effects of the immunological release of histamine upon human lung cyclic nucleotide levels and prostaglandin generation. J Clin Invest 1978;62:1113-21.

13. Lorenz W, Doenicke A. $\mathrm{H}_{1^{-}}+\mathrm{H}_{2}$-blockade: a prophylactic principle in anesthesia and surgery against histamine-release responses of any degree of severity. N Engl Reg Allergy Proc (Part I) 1985;6:37-57; (Part II) 1985;6:174-94.

14. Moss J, Rosow CE. Histamine release by narcotics and muscle relaxants in humans. Anesthesiology 1983;59:330-9.

15. Philbin DM, Moss J, Akins CW, et al. The use of $\mathrm{H}_{1^{-}}+\mathrm{H}_{2}-$ histamine antagonists with morphine anesthesia: a double-blind study. Anesthesiology 1981;55:292-6.

16. Moss \}, Roizen MF, Nordby EJ, et al. Decreased incidence and mortality of anaphylaxis to chymopapain. Anesth Analg 1985; 64:1197-1201.

17. Church $M K$, Gradidge CF. Inhibition of histamine release from human lung in vitro by antihistamines and related drugs. $\mathrm{Br} \mathrm{J}$ Pharmacol 1980;69:663-7.

18. Lau HYA, Pearce FL. Dual effects of antihistamines on rat peritoneal mast cells: induction and inhibition of histamine release. Agents Actions 1985;16:176-8. 